\title{
Interaction of Fungicide Physical Modes of Action and Plant Phenology in Control of Stem Rust of Perennial Ryegrass Grown for Seed
}

\author{
W. F. Pfender, United States Department of Agriculture-Agricultural Research Service National Forage Seed Pro- \\ duction Research Center and Oregon State University Department of Botany and Plant Pathology, Corvallis 97331
}

\begin{abstract}
Pfender, W. F. 2006. Interaction of fungicide physical modes of action and plant phenology in control of stem rust of perennial ryegrass grown for seed. Plant Dis. 90:1225-1232.

Azoxystrobin provided protective and curative effects against stem rust (caused by Puccinia graminis subsp. graminicola) of inoculated perennial ryegrass under field conditions, significantly reducing disease severity compared with the nontreated check when applied as much as 15 days before infection or 14 days after infection. Propiconazole had a significant effect when applied 13, but not 15, days before infection or 7, but not 9, days after infection. Either fungicide was very effective when applied near the time of infection, and the effectiveness of each fungicide was well described by a second- or third-order polynomial with time (days or stem rust latent periods) as the independent variable. When symptomatic plants were sprayed with a fungicide, subsequent urediniospore production per pustule was reduced by $73 \%$ in propiconazoletreated plants and by $95 \%$ in azoxystrobin-treated plants. Azoxystrobin modestly but significantly reduced germinability of urediniospores from sprayed pustules, unlike propiconazole. These differences between the two fungicides in physical modes of action resulted in a marked difference in their effects on secondary, within-plant spread of the disease. In normal disease development, sporulation from the inner (adaxial) face of pustules on the flag-leaf sheath produces inoculum that leads to numerous contiguous secondary infections along the length of the emerging inflorescence, but only $7 \%$ of azoxystrobin-treated sheath pustules had sporulation from the adaxial surface compared with 72 and $90 \%$ of propiconazole-treated and nontreated pustules, respectively. Tillers treated with propiconazole early in the process of within-plant spread had significantly greater final stem rust severity than those treated with azoxystrobin at this time. Results of these experiments will allow effects of fungicide application to be incorporated into quantitative epidemic models that describe disease development as a function of environment and plant phenology.
\end{abstract}

Additional keywords: Lolium perenne

For plant diseases that are controlled with fungicides, a major goal for improving management is to optimize timing of fungicide applications, thereby reducing their number to the minimum required for acceptable yield and quality. Optimum timing depends on the overall effect of a fungicide on disease development, which includes toxicity to the pathogen and additional characteristics referred to as physical modes of action $(7,16,18)$. The physi-

\section{Corresponding author: W. F. Pfender \\ E-mail: pfenderw@onid.orst.edu}

The use of trade, firm, or corporation names in this publication is for the information and convenience of the reader. Such use does not constitute an official endorsement or approval by the United States Department of Agriculture or the Agricultural Research Service of any product or service to the exclusion of others that may be suitable.

Accepted for publication 19 May 2006.

\section{DOI: 10.1094/PD-90-1225}

This article is in the public domain and not copyrightable. It may be freely reprinted with customary crediting of the source. The American Phytopathological Society, 2006. cal modes of action are defined by duration and degree of protective activity (fungicide applied prior to infection) and curative activity (fungicide applied after infection), effect of post-symptom application on spore production, and movement of the fungicide to nontreated parts of the plant. As disease warning and management models become more precise, information about fungicide physical modes of action is needed to make best use of the models for optimum fungicide timing.

In fields of perennial ryegrass (Lolium perenne L.) grown for seed, the major disease constraint in the United States and New Zealand is stem rust caused by Puccinia graminis Pers.:Pers. subsp. graminicola Z. Urban. This disease is managed with fungicides $(6,17)$ that typically are applied three to five times during the growing season in the Pacific Northwest of the United States, where most perennial ryegrass seed is produced. The fungicides of choice in this region are triazoles (principally propiconazole and tebuconazole) and strobilurins (principally azoxystrobin).

Triazoles and strobilurins are known to have some degree of acropetal systemic movement in plants $(4,8)$; however, the levels of protective and curative activity can vary among fungicides and even among pathosystems for a single fungicide $(10,18)$. Triazoles are sterol synthesis inhibitors and many have good activity against rust diseases (8). Propiconazole is protective for 2 to 3 days before infection and curative for up to 8 days after infection against chrysanthemum white rust ( $P$. horiana) (3). Tebuconazole has moderate protective and curative activity against $P$. recondita on wheat (4). In a comparison of Puccinia spp. affecting ornamental plants, propiconazole was an effective protectant against daylily rust but not against geranium rust, and had different levels of curative activity among three rust diseases (10). Triazoles generally have little effect on fungal spore germination, due to the timing of sterol synthesis and precursor accumulation during germination (15). Spores of $P$. graminis, in particular, apparently use endogenous sterol reserves for the first 6 to $8 \mathrm{~h}$ of germination and, thus, are insensitive to triademefon (a triazole) at this point in the life cycle (15). Propiconazole reduced, but did not inhibit completely, germination of urediniospores of several rust pathogens of ornamental plants, and its activity was fungistatic rather than fungitoxic (11).

Strobilurins interfere with respiratory chain enzymes and generally are very effective against rust diseases (4). Azoxystrobin has significant protective effect (as much as 15 days prior to inoculation) and curative activity ( 7 days post inoculation) against three Puccinia spp. on their ornamental hosts (10). This fungicide also is effective against $P$. recondita in wheat, where it is acropetally translocated within the leaves and has curative activity 5 days after infection (4). The related strobilurin fungicide kresoxim-methyl is reported to be protective, but not curative, against the same pathogen (5). Strobilurins are strongly inhibitory to germination of fungal spores $(2,9)$, and were shown to be toxic to urediniospores of several rust pathogens of ornamental crops after very short exposure times (11). In addition, these fungicides can inhibit sporulation from lesions in some pathosystems when applied post infection or post symptom development $(18,19)$.

We currently are developing an epidemic model that uses weather data to estimate infection severity and disease development for stem rust of perennial 
ryegrass $(12,13)$. To incorporate optimized fungicide use into this model, information about the physical modes of action for propiconazole and azoxystrobin is needed. Duration and degree of protective or curative activity would affect a fungicide's impact on the weather-related infection events specified in the epidemic model. In addition, the model specifies the dynamics of a unique type of within-plant disease spread related to grass phenology, in which any single lesion of stem rust on a leaf sheath can produce multiple, contiguous lesions on the enclosed stem or inflorescence as it elongates (14). This process can account for over $50 \%$ of final stem rust severity in a crop. Therefore, information about fungicide physical modes of action with respect to this secondary spread process is of overriding importance in optimizing fungicide application timing. There are no reports of physical modes of activity for these fungicides against stem rust on any host. Experiments described here were conducted to provide quantitative information about physical modes of action for the fungicides used to manage stem rust of perennial ryegrass grown for seed, and the resultant effect of fungicide timing on within-plant spread of the pathogen.

\section{MATERIALS AND METHODS}

Protective and curative activity of fungicides. A field experiment was conducted twice in 2001 and once in 2003 to determine protective and curative properties of propiconazole and azoxystrobin when applied at various durations before and after an infection event. These three trials of the experiment were conducted in the field, to include the effect of natural growing conditions on the persistence and activity of the fungicides. Disease severity from an inoculation in the field is highly dependent upon weather conditions (13). Therefore, it was decided to conduct each trial with a single infection event (all treatments inoculated on the same date) and various fungicide application times, rather than a single fungicide application time with several infection events.

Perennial ryegrass cv. Morningstar was planted in rows $30 \mathrm{~cm}$ apart on 10 October 2000 (for the 2001 trials) and 6 October 2002 (for the 2003 trial). For each trial, a plot 3 by $26 \mathrm{~m}$ within the planting was used. In the plot, alternate rows of the crop were mowed, as were 42 -cm-wide strips perpendicular to the rows, so as to leave $55-\mathrm{cm}$ lengths of nonmowed row available for treatment. Each $55-\mathrm{cm}$ section served as a replicate and received a single treatment (one fungicide treatment at one application date); there were four replicates per treatment in a completely randomized design. There were two check treatments (four replicates each) in which no fungicide was used; one was inoculated with the pathogen and the other was left noninoculated as a check on background levels of disease. In the three trials of this experiment, fungicide application timings ranged from 15 days before inoculation to 14 days after inoculation (Table 1), with the actual intervals depending upon when conditions were favorable for fungicide sprays and for inoculation with the pathogen. To apply fungicide to a replicate, the $55-\mathrm{cm}$ section of grass was enclosed with a fence (enclosure $55 \mathrm{~cm}$ long by $30 \mathrm{~cm}$ wide by $80 \mathrm{~cm}$ tall) of solid plastic to prevent fungicide spray reaching other replicates. Fungicide was applied through a single flat-fan TeeJet nozzle (no. 8002VS) attached to a $\mathrm{CO}_{2-}$ powered sprayer operating at $138 \mathrm{kPa}$ pressure. The nozzle was attached to a boom resting across the top of the rectangular enclosure and was pushed across the rectangle at the rate of $2 \mathrm{~s}$ per $55 \mathrm{~cm}$, delivering fungicide solution at $50 \mathrm{ml} / \mathrm{m}^{2}$ to the replicate. Fungicide solutions were prepared in water as follows: propiconazole (Tilt 428C; Syngenta, Inc., Basel, Switzerland) $374 \mathrm{mg}$ of active ingredient per liter (a.i. liter), and azoxystrobin (Quadris 2.08EC; Syngenta, Inc.) $325 \mathrm{mg}$ a.i. liter amended with $1 \%$ (vol:vol) nonionic surfactant (Agridex, Helena, MT). Thus, the rates of fungicide application were equal to standard, labeled rates of Tilt at $189 \mathrm{~g}$ a.i. ha and Quadris at $165 \mathrm{~g}$ a.i. ha.

The inoculum consisted of urediniospores of $P$. graminis subsp. graminicola that had been collected from field plantings of perennial ryegrass the prior year, dried overnight, stored at $-60^{\circ} \mathrm{C}$, and heat shocked before use as described previously (14). The field populations of $P$. graminis subsp. graminicola from which the inoculum was collected were in a seedproduction area where triazole fungicides have been used for over 25 years and stro- bilurins have been in common use for about 8 years. A suspension of urediniospores (approximately $3.8 \times 10^{6}$ spores $/ \mathrm{ml}$ ) was prepared for each replicate by mixing $9 \mathrm{mg}$ of spores in $750 \mu \mathrm{l}$ of light mineral oil (Soltrol; Phillips Petroleum Co., Bartlesville, OK). Each 750- $\mu$ l aliquot was mixed thoroughly immediately before being sprayed onto a replicate, with the use of a small, handheld Venturi atomizer (1) operating at $34 \mathrm{kPa}$. To contain the inoculum on the target replicate, the rectangular enclosure described previously was set around it before application; a covering of plastic sheeting with a slit for the operator's hand was placed on the top of the rectangular enclosure. Inoculations were done between 9:00 a.m. and 12:00 noon. To avoid the phytotoxicity that results from mixing of water with the oil before it dries, plants were kept clear of dew by covering the plot with a temporary tent during the night preceding the inoculation day. The tent was removed before inoculation if rain was not threatening; otherwise, it was removed as soon as the oil was dry (1 to 2 $\mathrm{h}$ after inoculation). The favorability of the weather for infection during the night and morning following inoculation was calculated (13) from temperature and leaf wetness data collected in the plot, and is shown in Table 1.

Approximately 1.6 latent periods (LPs) after inoculation (14 to 21 days after inoculation, as calculated [12] from temperatures during the interval), plants were scored for disease severity. The plants from a $20-\mathrm{cm}$-long section of row within the $55-\mathrm{cm}$ replicate were cut as a sample, from which 50 tillers were taken at random to count the number of pustules per tiller. The average number of pustules per tiller was used as the replicate value in the statistical analysis. Mean and standard error were computed for each treatment, and Dunnett's test was used to compare each sprayed treatment with the inoculated check. In addition, a two-way analysis of variance (ANOVA) was done within each trial (fungicide and timing as factors). A regression analysis was done for the combined results of the three trials for each fungicide, to assess the relationship between time of application (before and after infection) with disease severity. Time was expressed as days or as LPs (a heat unit

Table 1. Field experiment to measure protective and curative activity of azoxystrobin and propiconazole against stem rust of perennial ryegrass

\begin{tabular}{|c|c|c|c|c|c|}
\hline \multirow[b]{2}{*}{ Trial } & \multirow[b]{2}{*}{ Planting date } & \multicolumn{3}{|c|}{ Inoculation $^{x}$} & \multirow[b]{2}{*}{ 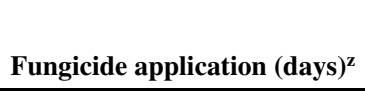 } \\
\hline & & Date & Plant stage & Infection value $y$ & \\
\hline I & 10 October 2000 & 16 May 2001 & Feeke's 10.1 & 2.2 & $-13,-7,-1,+2,+5,+7$ \\
\hline II & 10 October 2000 & 5 June 2001 & Feeke's 10.5.1 & 2.6 & $-15,-7,-1,+3,+7,+9$ \\
\hline III & 6 October 2002 & 20 May 2003 & Feeke's 10.2 & 3.0 & $-7,-1,+1,+7,+14$ \\
\hline
\end{tabular}


calculation equal to the duration of one LP in this pathosystem) (12) and disease was normalized among trials by expressing it as a proportion of the disease severity on the respective inoculated check. All analyses were computed using SigmaStat software (SPSS, Inc., Chicago).

Production and germinability of spores from fungicide-treated plants. Fieldgrown perennial ryegrass plants were transplanted to pots at 2 months of age, then maintained outdoors until used in experiments. Potted plants were brought into a greenhouse and inoculated with urediniospores of $P$. graminis subsp. graminicola as described previously (14), using a spore suspension of $2 \mathrm{mg}$ of spores $/ \mathrm{ml}$ of Soltrol oil. Inoculated plants were kept in a mist chamber overnight at $16^{\circ} \mathrm{C}$, then allowed to dry gradually while exposed to light and temperatures increasing to $25^{\circ} \mathrm{C}(13)$. Plants were maintained in a greenhouse with day and night temperatures of 18 and $15^{\circ} \mathrm{C}$, respectively, until pustules erupted 9 days later. Pots were divided randomly into three treatment groups: two fungicides and the check (water-only) treatment. Potted plants were placed upright on the ground and the area was sprayed using a backpack sprayer operating at $138 \mathrm{kPa}$ and groundspeed required to deliver propiconazole at $189 \mathrm{~g}$ a.i. or azoxystrobin at $165 \mathrm{~g}$ a.i. in 170 liters of water/ha. Two days after fungicide treatment, accumulated urediniospores were removed and discarded from randomly selected pustules by gently vacuuming with a miniature cyclone sampler (1), taking care not to damage the uredinia. This procedure removed spores that may have been produced before fungicide treatment, as well as fungicide that may have been deposited on the pustules. Then, 2 days later (4 days after fungicide treatment), newly produced urediniospores were collected with the cyclone sampler from each of five previously cleaned pustules per treatment, and the spores were counted with the aid of a hemacytometer after suspending them in light mineral oil. Germinability of urediniospores from five additional pustules per treatment also was assessed. For the germination test, a leaf segment bearing a single pustule was cut from the plant and gently tapped while holding it above a plate of water agar, to release spores onto the agar surface. Plates were kept in the dark at $24^{\circ} \mathrm{C}$ for $24 \mathrm{~h}$, then germination was assessed by microscopic examination of 100 spores/ pustule. Spores were considered germinated if the germ tube was at least as long as the spore diameter.

The experiment was conducted twice (two trials). Data were transformed to the logarithms of the observed values to equalize the variance before conducting a twoway ANOVA with fungicide treatment and trial as the factors.

Effect of fungicides on within-plant disease spread. Perennial ryegrass plants undergoing reproductive growth were obtained as described previously (14), by transplanting vernalized plants from the field into pots in a greenhouse. When tillers reached the phenological stage of flagleaf sheath exposure, they were inoculated to produce a single lesion on the flag leaf sheath. A spore suspension was prepared (6 mg of urediniospores in $1 \mathrm{ml}$ of Soltrol oil) and a small amount was applied to one 5-mm-diameter spot on each flag leaf sheath by means of a small paintbrush. The inoculated spot was located on the opposite side of the sheath from the overlapping leaf edges and 1 to $2 \mathrm{~cm}$ below the junction of the leaf blade and sheath. Tillers were tagged individually for future identification, and flag leaf sheath lengths were recorded. After the Soltrol oil had evaporated, plants were exposed overnight to conditions favorable for infection (14), then maintained in a greenhouse where they were irrigated without allowing water to contact leaves or stems. A datalogger in the greenhouse recorded temperature every half-hour during the experiments, for calculating LP durations (12).

Previous research (14) had shown that urediniospores are released from the inner face of the infected sheath at the pustule site when the pustule erupts, one LP after the primary infection occurs on the sheath surface. These spores then initiate multiple secondary infections on the stem as it extends from within the enclosing sheath. In the experiment reported here, the fungicides were applied after the secondary infections had begun (i.e., >1 LP after inoculation), to determine fungicide curative effects on the secondary stem infections as well as fungicide effects on within-plant spread via effects on sporulation of the primary pustule or subsequent infection processes. Preliminary experiments suggested that fungicide activity on secondary infections could differ with their physical exposure to the fungicides and with the relative timings of the infection event and the fungicide application (Fig. 1). For example, secondary infections on that portion of the inflorescence that had extended above the flag leaf sheath by the time of fungicide application (Fig. 1, segment B) may respond differently to fungicide application than secondary infections on the portion of the inflorescence that has not yet emerged above the sheath (Fig. 1, segment C).

The experiment to measure effects of fungicide application on secondary, within-plant spread of stem rust was conducted twice. In the first trial, fungicide was applied to some plants at 1.1 LP after sheath inoculation and to others at $1.6 \mathrm{LP}$ post inoculation. In the second trial, fungicide application was done at 1.2 and 1.8 LP post inoculation. To ensure that adequate fungicide coverage of the inoculation site would occur, fungicide was applied after laying the potted plants on their sides on the ground, with the inoculated side of the tiller facing up. $\mathrm{A} \mathrm{CO}_{2}$-powered backpack sprayer was used to apply the fungicide through a TeeJet flat fan nozzle, with the operator walking at a speed to apply propiconazole at $189 \mathrm{~g}$ a.i. or azoxystrobin at $165 \mathrm{~g}$ a.i. in 170 liters of water/ha. The azoxystrobin solution was amended with surfactant as previously described. After the fungicide dried on the plants, they were returned to the greenhouse and maintained as described previously.

Measurements of stem lengths and lesion location on each inoculated tiller were taken periodically (including at times of inoculation, eruption of primary pustule, and fungicide application) to permit later identification of the segments illustrated in Figure 1. After inflorescence extension was complete (approximately 21 days after inoculation; Fig. 1, time 3), one additional LP was allowed to pass so that all latent secondary infections on the inflorescence had time to erupt. Then, 30 days after inoculation of the sheath, the length and location of secondary infections on the inflorescence were measured and mapped onto diagrams of the inoculated tillers. Locations and lengths of the three segments B through D (Fig. 1), derived as described in the previous paragraph, were superimposed on the disease diagrams. Disease severity, as the length (in centimeters) of inflorescence bearing pustules, was recorded for each segment.

The experimental unit was one pot and there were two inoculated tillers per pot. Measurements from the two tillers/pot were averaged to produce the replicate value for analysis, and there were eight replicate pots/treatment. The design of the experiment was completely randomized. ANOVA was used to compare full-tiller disease severity (percent total stem length diseased as a proportion of this value for inoculated, nontreated check plants) across fungicides and application times. For each date-of-application treatment within each trial, a $t$ test was used to compare propiconazole-treated and azoxystrobin-treated tillers for disease severity (proportion of the stem length that was rusted) for each of the three stem segments $(\mathrm{B}, \mathrm{C}$, and $\mathrm{D})$ shown in Figure 1.

\section{RESULTS}

Protective and curative activity of fungicides. In-field inoculation of perennial ryegrass with $P$. graminis subsp. graminicola was successful, but the disease severities (number of pustules per tiller) differed among the three trials of the experiment (Fig. 2), perhaps due to different weather conditions immediately following inoculation (Table 1). Inoculated, nontreated checks averaged 2.5, 6.2, and 17.1 pustules/tiller in the three trials, respectively. Noninoculated checks had very little stem rust $(0.02,0.3$, and 0.1 pustules/tiller, respectively), indicating that 
background levels of disease were not important compared with the severity produced by the single inoculation event in each trial. For each trial, most fungicide treatments had significantly $(P<0.05$, Dunnett's test) less disease than the respective inoculated check, except for propiconazole treatments 15 days before infec-

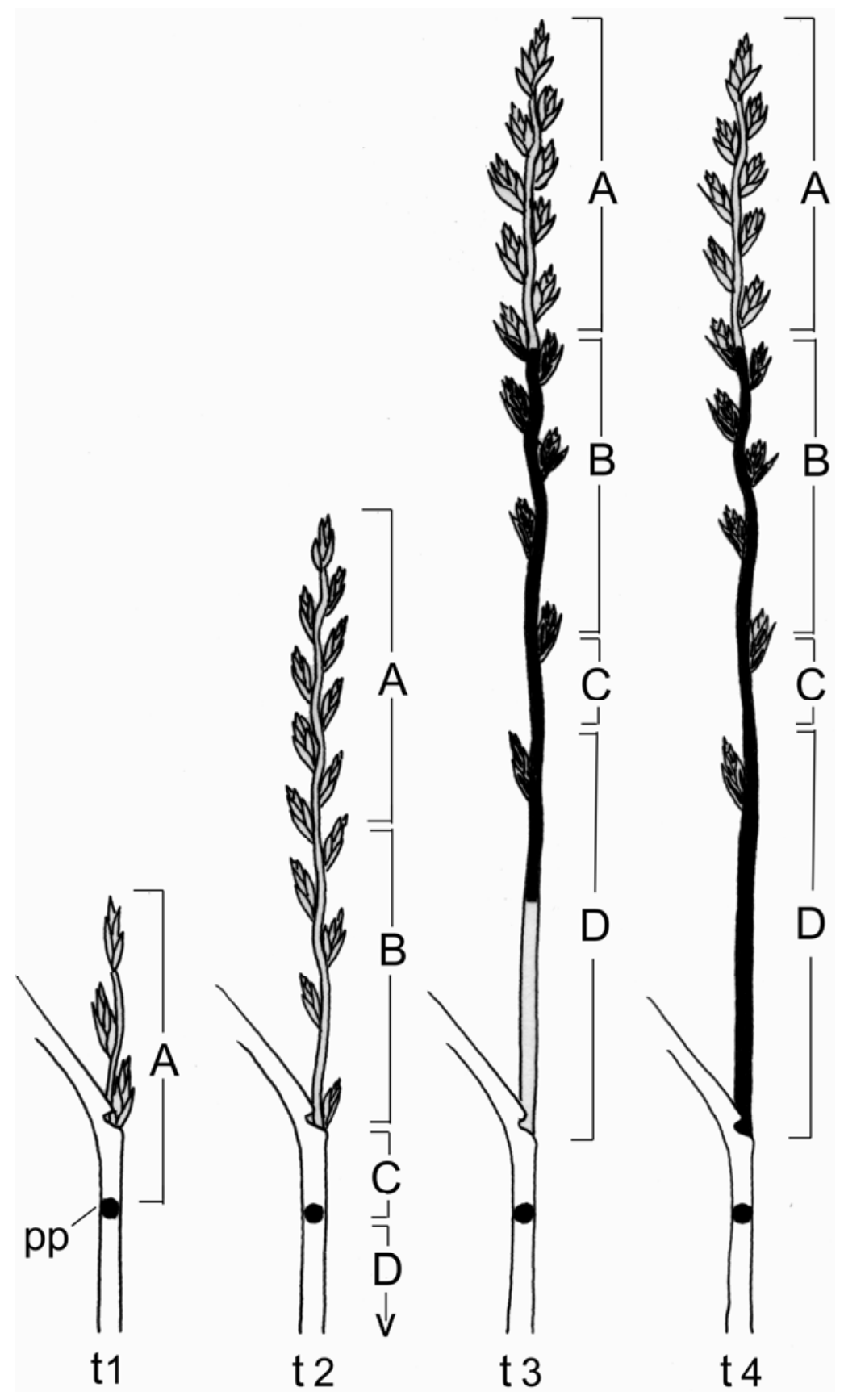

Fig. 1. Areas of secondary disease relative to fungicide application. Secondary, within-plant spread of disease begins at time $\mathrm{t} 1$, when a primary pustule (pp) from an infection on the outer surface of the leaf sheath first erupts on the plant surface. This pustule also releases urediniospores from the inner (adaxial) surface of the sheath, and these spores initiate secondary infections along the length of the enclosed inflorescence as it extends. Segment A of the inflorescence, distal to the primary infection site at time t1, does not receive secondary inoculum. At the time of fungicide application, shown here arbitrarily as time $\mathrm{t} 2$, four regions of the expanding inflorescence can be designated with respect to fungicide exposure. Segment $\mathrm{B}$ has been exposed to secondary inoculum prior to fungicide application and is now exposed to direct fungicide contact. Segment $\mathrm{C}$ has been exposed to secondary inoculum prior to fungicide application but is shielded from direct fungicide contact by the sheath distal to the primary infection site. Segment $\mathrm{D}$ has not been exposed to secondary inoculum at the time fungicide is applied; secondary infections on this part of the inflorescence proximal to the site of primary infection can only occur after time $t 2$, as inflorescence extension continues. At time $\mathrm{t} 3$, the inflorescence has completely extended and all four regions are exposed. For purposes of illustration, all secondary infections (designated as solid black fill) have been successful. Sufficient time has passed between times $\mathrm{t} 2$ and $\mathrm{t} 3$ for the secondary infections to have erupted in segments B, C, and part of D. The nonlesioned, lower part of segment D bears latent infections which become erumpent by the time another latent period has passed (time t4). tion or $\geq 9$ days after infection. Two-way ANOVA on the data for each trial showed a significant effect $(P<0.05)$ for day of treatment (i.e., fungicides were more effective when applied close to the time of infection than when applied earlier or later). The main effect for fungicide (propiconazole versus azoxystrobin) was significant $(P<0.05)$ in trials II and III, but not in trial I.
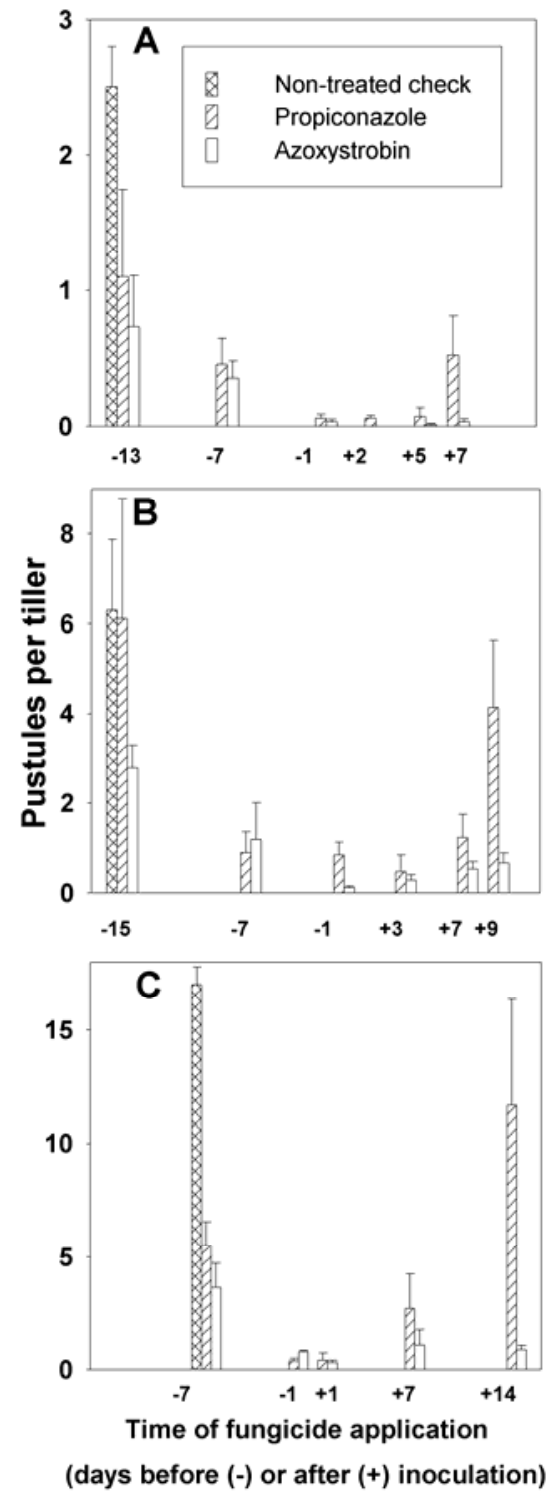

Fig. 2. Stem rust severity in field experiment of perennial ryegrass treated with fungicides before or after inoculation. Disease severity (pustules per reproductive tiller) of fieldgrown perennial ryegrass plants inoculated with Puccinia graminis subsp. graminicola and treated with propiconazole (189 mg a.i. per ha) or azoxystrobin (165 $\mathrm{mg}$ a.i. per ha) at various times before or after inoculation. Three different field trials are illustrated (A, B, and $\mathbf{C})$, and severity in the inoculated, nontreated check is placed at the left of each graph for convenience. The data were collected at 1.6 latent periods after infection. Vertical lines above bars indicate standard error. There were four replicate plots per treatment in each trial of the experiment, and 50 tillers sampled per replicate. 
When data from the three trials were combined in a regression analysis (Fig. 3), the effect of application timing on fungicide activity was significant $(P<0.01)$ for each fungicide. When applied near the time of infection, each fungicide reduced disease nearly to zero (Fig. 3). As the time between pre-infection (protective) application and infection increased, the degree of fungicide activity decreased, and the decrease was sharper for propiconazole than for azoxystrobin. In post-infection treatment, azoxystrobin showed more prolonged curative effects than did propiconazole (e.g., 90 versus $30 \%$ control, respectively, when applied 14 days after infection). Expressing time before and after infection in terms of heat units (LP units for the pathogen) rather than chronological time produced a slightly better correlation with fungicide effect $\left(r^{2}=\right.$ 0.90 versus 0.83 for propiconazole and 0.91 versus 0.90 for azoxystrobin, respectively; Fig. 3C).

Production and germinability of spores from fungicide-treated plants. Urediniospores, produced between 2 and 4 days after pustules were sprayed with propiconazole at labeled rates, were unaffected in their viability (93\%) compared with the spores from nontreated checks (98\%) (Table 2). Azoxystrobin, in contrast, reduced germinability of spores significantly $(P<0.05)$ to $82 \%$.

Between 2 and 4 days after plants were sprayed with propiconazole, the number of urediniospores produced per pustule was only $27 \%$ of the number produced by pustules on nontreated plants. Pustules on azoxystrobin-treated plants produced only $5 \%$ as many spores as pustules on the nontreated plants. All three treatments (azoxystrobin, propiconazole, and check) were significantly $(P<0.05)$ different from one another (Table 2).

Effect of fungicides on within-plant disease spread. When plants were inocu- lated at a single site on the flag leaf sheath, the severity of secondary disease from within-plant spread was greatly affected by fungicide type and application timing (Fig. 4). Plants treated with propiconazole ultimately had approximately $80 \%$ as much disease as nontreated plants when the fungicide was applied early in the secondaryinfection process (1.1 LP after primary infection, which is $0.1 \mathrm{LP}$ after presumed start of secondary infections). As time of propiconazole treatment was delayed, final disease severity decreased to reach approximately $20 \%$ of the nontreated checks in plants treated 1.8 LP after primary infection. In contrast, azoxystrobin treatment during secondary, within-plant disease spread reduced final disease severity to between 15 and $20 \%$ of that in the check, whether treatment occurred at 1.1, 1.2, 1.6, or $1.8 \mathrm{LP}$ after initial infection (Fig. 4).

A more detailed examination of this difference between fungicides revealed a pattern in the distribution of secondary infections along the inflorescence (Table 3). A $t$ test was used to compare the two fungicides for proportion of diseased length of each tiller segment in each of four cases (two application times in each of two trials, with eight replicates per treatment in each case). In segment B, which is the portion of the inflorescence where secondary infections were exposed directly to applied fungicides (Fig. 1), propiconazole and azoxystrobin were similar in their effects in two of three cases (in the early-timed application of trial II there was no segment B, because the infected segment had not emerged from the enclosing sheaths when fungicides were applied). Azoxystrobin was significantly more effective against these infections than propiconazole was in one case. The fungicides usually did not differ $(P<0.05)$ in their effects on secondary infections that were still covered by the enclosing sheath at the time of application (Fig. 1, segment C; Table 3). Again in the case where the difference was significant, azoxystrobin reduced disease more than propiconazole

Table 2. Production and germinability of urediniospores of Puccinia graminis subsp. graminicola from perennial ryegrass plants treated with fungicides

\begin{tabular}{lcc}
\hline & \multicolumn{2}{c}{ Urediniospore assay $^{\mathbf{w}}$} \\
\cline { 2 - 3 } Fungicide $^{\mathrm{x}}$ & $\begin{array}{c}\text { Spores per } \text { pustule }^{\mathbf{y}} \\
\text { Germination } \\
(\boldsymbol{\%})^{\mathbf{z}}\end{array}$ \\
\hline None (check) & $4,074 \mathrm{a}$ & $98 \mathrm{a}$ \\
Propiconazole & $1,114 \mathrm{~b}$ & $93 \mathrm{a}$ \\
Azoxystrobin & $184 \mathrm{c}$ & $82 \mathrm{~b}$ \\
\hline
\end{tabular}

${ }^{\mathrm{w}}$ Two days after fungicide sprays were applied, arbitrarily-selected pustules were gently vacuumed to remove any accumulated urediniospores. Two days later, spores were collected from each pustule for analysis of the spores produced between days 2 and 4 after fungicide application. Different pustules were used for production and germinability analyses.

${ }^{x}$ Perennial ryegrass plants were inoculated with $P$. graminis subsp. graminicola and maintained in the greenhouse until erumpent pustules appeared. Two days after pustules erupted (11 days after inoculation), plants were sprayed with propiconazole (Tilt at a rate of $182 \mathrm{~g}$ a.i./ha) or azoxystrobin (Quadris at a rate of $150 \mathrm{~g}$ a.i./ha) or left nontreated. Plants were maintained in the greenhouse after treatment.

$y$ Each value represents the number of spores produced between 2 and 4 days after fungicide application. Values followed by the same letter do not differ $(P<0.05)$, by the Student-Newman-Keuls test.

${ }^{\mathrm{z}}$ Urediniospores were collected onto the surface of a plate of water agar on day 4 and incubated in darkness at $24^{\circ} \mathrm{C}$ for $24 \mathrm{~h}$ before assessing germination. A spore was considered germinated if the germ tube length exceeded the spore diameter. In all, 100 spores/replicate were counted, and there were five replicate pustules per treatment in each of two experiments. Values followed by the same letter do not differ $(P<0.05)$, by the Student-NewmanKeuls test.

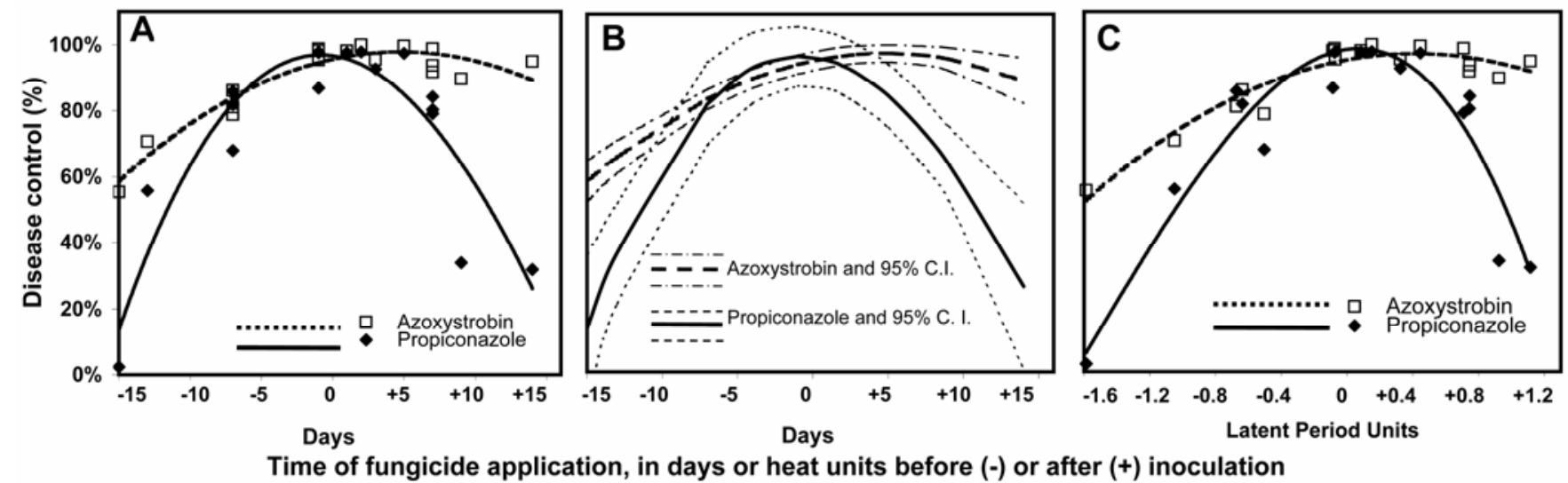

Fig. 3. Protective and curative activity of fungicides against stem rust of perennial ryegrass in field plots. Data from three field trials normalized to disease severity as a proportion of that in the respective inoculated check, and expressed as percent control (100 - percent relative severity). A, Data points and regression line for effectiveness of propiconazole $\left(y=96.6-0.182 x-0.368 x^{2}, r^{2}=0.83\right)$ or azoxystrobin $\left(y=95.6-0.968 x-0.10 x^{2}, r^{2}=0.90\right)$, where $y$ is percent control and $x$ is the number of days between fungicide application and inoculation. B, The regression lines of Figure $3 \mathrm{~A}$ with associated boundaries for the $95 \%$ confidence interval of the regression. C, Data points and regression line for effectiveness of propiconazole or azoxystrobin as a function of latent period (LP) units between fungicide application and preceding or ensuing inoculation. Propiconazole: $y=96.8-6.34 x-49.0 x^{2}-10.1 x^{3}\left(r^{2}=0.90\right)$. Azoxystrobin: $y=95.3-9.46 x-11.1 x^{2}\left(r^{2}=0.91\right)$, where $y$ is percent control and $x$ is LP units. 
did. The major difference between the fungicides in their effect on within-plant spread of stem rust was seen in segment D (Fig. 1), which bears the secondary infections that are initiated after the time of fungicide application (Table 3). In three of four cases, propiconazole permitted significantly $(P<0.05)$ more secondary disease development on this segment than azoxystrobin did. It is notable that, in the case where the difference was not significant, the segment length available for this

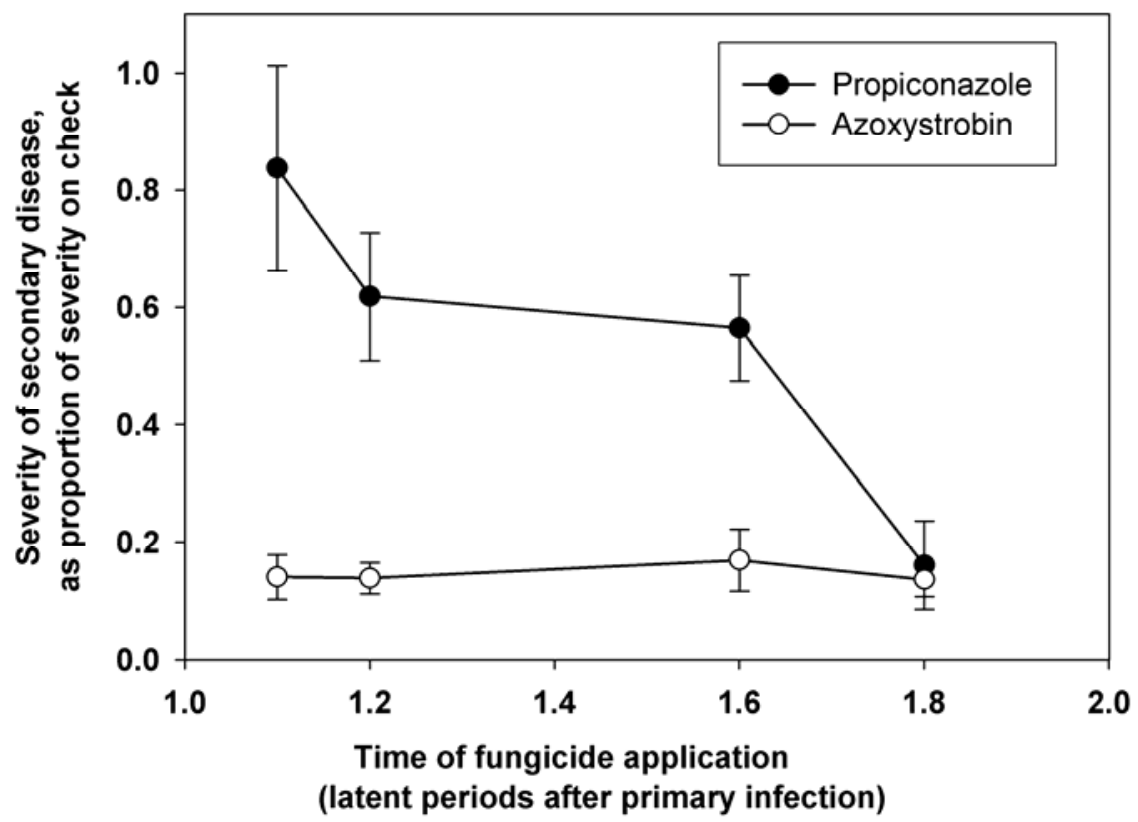

Fig. 4. Effect of fungicides on stem rust severity resulting from secondary, within-plant spread of disease. Each tiller was inoculated to produce a single primary pustule on the flag leaf sheath, then sprayed with propiconazole or azoxystrobin at one of the times indicated. Time is expressed as latent periods (LPs) after primary infection; $1 \mathrm{LP}$ is equivalent to approximately 8 days under the conditions of this greenhouse experiment. Sprays were applied at 1.1 or $1.6 \mathrm{LP}$ in one trial, and at 1.2 or $1.8 \mathrm{LP}$ in a second trial. Length $(\mathrm{cm})$ of the diseased portion of the inflorescence was measured $4 \mathrm{LP}$ after primary infection. Severity is expressed as percentage of the diseased proportion of the inflorescence on nontreated (check) tillers in the same trial. The bars indicate \pm standard error. type of infection was relatively short due to the fungicide application being quite late in the process of secondary infection, when there is little stem extension remaining (Table 2). The weighted average disease severity (proportion rusted $\times$ segment length) for segment $\mathrm{D}$ across the four application times was $33 \%$ for propiconazole and only 5\% for azoxystrobin. An examination of the inner sheath surfaces directly under the initial inoculation sites at the end of the experiment showed that only $7 \%$ of the azoxystrobin-treated plants had urediniospores at these sites, significantly $(P<$ $0.05)$ less than the $72 \%$ of the propiconazole-treated plants or the $90 \%$ of the nontreated check plants that had abundant spores there.

\section{DISCUSSION}

Azoxystrobin and propiconazole each provided significant protective and curative activity against stem rust of perennial ryegrass when tested under field conditions. The observed protective activity of azoxystrobin (significantly less disease than the check when applied 15 days prior to infection) is similar to that reported for three rust diseases of ornamentals (10), which were significantly reduced by an application 15 days before infection. Other reports $(3,4)$ also show significant protective activity against rusts, although none tested as great a time period. We observed curative activity against stem rust from applications of azoxystrobin made as many as 14 days $(1.1 \mathrm{LP})$ after infection. In other reports $(3,4,10)$, curative activity of this fungicide against other rust diseases was significant

Table 3. Comparison of secondary disease (proportion of vulnerable stem rusted) on tillers treated with propiconazole or azoxystrobin at indicated times after primary infection on the sheath

\begin{tabular}{|c|c|c|c|c|c|c|c|c|c|c|c|}
\hline \multirow{3}{*}{\multicolumn{3}{|c|}{$\frac{\text { Fungicide application }^{\mathrm{x}}}{\text { Time after primary infection }}$}} & \multirow[b]{4}{*}{ Material } & \multicolumn{8}{|c|}{ Disease severity on inflorescence exposed to secondary infectiony } \\
\hline & & & & \multicolumn{2}{|c|}{ Segment B } & \multicolumn{2}{|c|}{ Segment $\mathrm{C}$} & \multicolumn{2}{|c|}{ Segment D } & \multicolumn{2}{|c|}{ Full-length } \\
\hline & & & & \multirow{2}{*}{$\begin{array}{l}\text { Length } \\
(\mathrm{cm})\end{array}$} & \multirow{2}{*}{$\begin{array}{c}\text { Proportion } \\
\text { rusted }\end{array}$} & \multirow{2}{*}{$\begin{array}{l}\text { Length } \\
(\mathbf{c m})\end{array}$} & \multirow{2}{*}{$\begin{array}{c}\text { Proportion } \\
\text { rusted }\end{array}$} & \multirow{2}{*}{$\begin{array}{l}\text { Length } \\
\text { (cm) }\end{array}$} & \multirow{2}{*}{$\begin{array}{c}\text { Proportion } \\
\text { rusted }\end{array}$} & \multirow{2}{*}{$\begin{array}{c}\text { Length } \\
(\mathbf{c m})\end{array}$} & \multirow{2}{*}{$\begin{array}{l}\text { Proportion } \\
\text { rusted }\end{array}$} \\
\hline Trial & Days & LP & & & & & & & & & \\
\hline \multirow[t]{3}{*}{$\bar{I}$} & 10 & 1.1 & Propiconazole & 0.88 & $0.01 \mathrm{~ns}$ & 0.99 & $0.39 \mathrm{~ns}$ & 28.56 & $0.31 *$ & 30.43 & 0.30 \\
\hline & & & Azoxystrobin & 0.82 & 0.00 & 0.83 & 0.27 & 27.71 & 0.04 & 29.36 & 0.05 \\
\hline & & & None & & 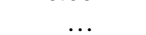 & & & & & 36.52 & 0.36 \\
\hline \multirow[t]{3}{*}{ II } & 11 & 1.2 & Propiconazole & $0.00^{\mathrm{z}}$ & $\ldots$ & 2.46 & $0.84 \mathrm{~ns}$ & 19.03 & $0.44 *$ & 21.49 & 0.48 \\
\hline & & & Azoxystrobin & 0.00 & $\ldots$ & 1.94 & 0.73 & 20.39 & 0.04 & 22.33 & 0.11 \\
\hline & & & None & & $\ldots$ & $\ldots$ & & & & 25.66 & 0.77 \\
\hline \multirow[t]{3}{*}{ I } & 15 & 1.6 & Propiconazole & 14.36 & $0.11 *$ & 1.23 & $0.54 *$ & 14.90 & $0.25 *$ & 30.49 & 0.20 \\
\hline & & & Azoxystrobin & 12.76 & 0.01 & 1.06 & 0.18 & 14.87 & 0.10 & 28.68 & 0.06 \\
\hline & & & None & & & & & & & 36.52 & 0.36 \\
\hline \multirow{3}{*}{ II } & 17 & 1.8 & Propiconazole & 11.29 & $0.08 \mathrm{~ns}$ & 2.86 & $0.34 \mathrm{~ns}$ & 5.74 & $0.12 \mathrm{~ns}$ & 19.89 & 0.12 \\
\hline & & & Azoxystrobin & 12.41 & 0.03 & 2.82 & 0.53 & 4.74 & 0.04 & 19.97 & 0.10 \\
\hline & & & None & $\ldots$ & $\ldots$ & $\ldots$ & $\ldots$ & $\ldots$ & $\ldots$ & 25.66 & 0.77 \\
\hline
\end{tabular}

${ }^{x}$ Primary infection from applied inoculum resulted in a single pustule induced on the flag leaf sheath. Fungicides (propiconazole at $189 \mathrm{~g}$ a.i./ha and azoxystrobin at $165 \mathrm{~g}$ a.i./ha) were applied, as sprays simulating field application with complete coverage, at the indicated times after inoculation. Latent period (LP) is a heat-unit measure of the time needed to complete the pathogen's LP on this host species (12).

y Severity of secondary disease due to spread from primary pustule (on sheath) to enclosed, extending inflorescence. Severity measured 30 days after primary infection, expressed as diseased length (in centimeters) of inflorescence. Values are averages of eight replicates per treatment, two tillers/replicate. Segments B, C, and D designate portions of the inflorescence according to their exposure to secondary infection and fungicide treatment. Segment B was exposed to secondary infection, then direct fungicide contact; segment $\mathrm{C}$ was exposed to secondary infection, but shielded from direct fungicide contact by overlying sheath; and segment D was exposed to secondary infection only after fungicide application had occurred. Full-length is the sum of B, C, and D, representing the entire length that is exposed to secondary infection. Segments B, C, and D are defined with respect to fungicide application times and, thus, are not defined for nontreated checks. Paired tests of proportion rusted (propiconazole versus azoxystrobin within a treatment time) was done by the Mann-Whitney procedure; $*=$ difference significant at $P<0.05$ and ns $=$ not significantly different.

z There was no segment B in this trial, because the site of secondary infection had not emerged above sheath at the time of fungicide application. 
at the longest durations tested (5 to 8 days). Azoxystrobin had protective but no curative activity against grape downy mildew (18). In our study of stem rust, propiconazole had protective activity when applied at 13 , but not at 15 , days before infection; it had curative effects when applied at 7 , but not at 9 or 14 , days after infection. Protective activity of propiconazole against other rusts varies. Mueller et al. (10) observed no protective activity for propiconazole against geranium rust, but significant activity with a 15-day preinoculation treatment of daylily rust and sunflower rust. The experiments reported here were conducted under field conditions, including fungicide applications at labeled rates and typical spray volumes. The resultant data are somewhat variable, likely due to variability in infection levels and fungicide coverage, but probably are representative of protective and curative activity that would be experienced in actual agricultural use. It is clear that either fungicide is very effective when applied close to the time of infection, and that azoxystrobin has better protective and curative activity than propiconazole as the time interval between fungicide application and infection increases. It is possible that this difference in activity between the two fungicides reflects genetic selection due to the longer exposure history of the local stem rust fungus population to propiconazole than to azoxystrobin. However, it is noteworthy that qualitatively similar results with respect to differences in activity of these two fungicides have been reported for some other rust pathogens (10).

The observed effects of azoxystrobin and propiconazole on spore production and germinability are congruent with reports about other pathosystems. Azoxystrobin, applied post infection, effectively inhibited sporulation of the grape downy mildew fungus (18). We observed a significant reduction in urediniospore production (compared with the nontreated check) following post-symptom application of either azoxystrobin or propiconazole, although the effect was significantly greater on azoxystrobin-treated plants (Table 2). Pustules on azoxystrobin-treated plants not only produced fewer spores but the spores produced also had a reduced probability of germinating compared with those produced on propiconazole- or nontreated plants (Table 2). Previous reports have shown moderate (11) or no inhibition (2) of urediniospore germination by propiconazole, and irreversible toxicity by azoxystrobin, when spores are exposed directly to the fungicides $(2,11)$. This difference in degree of inhibition was supported by preliminary experiments (W. F. Pfender, unpublished) in which urediniospores were transferred in bulk from pustules to water agar immediately after diseased plants were treated with fungicide. In the experiment reported in Table 2, the combined effects of azoxystrobin on sporulation and germinability result in only $4 \%$ as many germinable spores per pustule as in the nontreated checks and $15 \%$ as many as in the propiconazoletreated plants. This reduction in germinable spores per pustule could produce a marked difference between azoxystrobin and propiconazole in their effects on plantto-plant spread, and, thus, epidemic progress.

In addition to possible effects on plantto-plant spread, differences between azoxystrobin and propiconazole on within-plant disease spread in this pathosystem could result in particularly stark differences in control of stem rust. As previously reported (14), most of the final disease severity in stem rust of perennial ryegrass grown for seed results from an adaptation of the pathogen to the host's growth habit, such that a single initial lesion on a leaf sheath can produce extensive secondary lesion areas on the extending stem. The contiguous stem lesions are the hallmark of stem rust disease, and they result in extensive damage and large numbers of urediniospores. The effect of a fungicide on this process is the combined outcome of its protective or curative activity and its activity against production of germinable spores. For infected stems that are exposed at the time of fungicide application (Fig. 1, segment B), the two fungicides are equivalent if applied early in the process. Azoxystrobin has a greater curative activity than propiconazole, however, so that, if the fungicides are applied when the infected sites of segment B are older than approximately 0.6 LP (Fig. 3C), azoxystrobin reduces disease severity more than propiconazole does. A more important difference is the effect of azoxystrobin on postsymptom spore production and germinability. The process of secondary infection occurring on the portion of the stem proximal to the initial sheath lesion at the time of fungicide application (Fig. 1, segment D) is largely unaffected by the application of propiconazole. However, azoxystrobin inhibits most of these secondary infections, presumably because of its postsymptom activity against spore production and germinability from the primary pustule. By interfering with the ability of the pathogen to produce germinable spores from the inner face of the pustule on the adaxial surface of the sheath, the contiguously infected length of extending stem or inflorescence is eliminated or greatly reduced. The difference in the capability of the two fungicides to affect the final disease severity depends greatly on the time of fungicide application relative to stem extension. Early in stem extension, segment D (secondary infections occurring after fungicide application; Fig. 1) represents a greater proportion of the final stem length than it does later in stem extension. Therefore, propiconazole is less effective than azoxystrobin when applied early in this process (Fig. 4). The effects of the fungicides on this process also depend on the location of the sheath lesions; note that neither fungicide is greatly inhibitory to existing infections that are covered by the sheath at the time of application (Fig. 1, segment C; Table 3). It should also be noted that effectiveness of fungicide application depends upon adequate coverage of plant surfaces with fungicide. In our experiments on within-plant spread of disease, we measured the outcomes for infection sites we knew to be adequately exposed to fungicide. Under field conditions, some infection sites will escape fungicide coverage. Our field experiments (Fig. 3) provide an efficacy estimate that includes variability due to coverage; a model for fungicide activity that accounts for coverage, timing, and phenological effects could be constructed by combining results in Figure 3 with those in Figure 4.

Physical modes of action can be very important to the outcome of fungicide application in disease control. The grass stem rust pathosystem is particularly sensitive to fungicide physical modes of action, as illustrated in this research. Quantitative knowledge of the preventative or curative and sporulation effects of the two fungicides most commonly used to manage stem rust in perennial ryegrass seed fields will enable construction of an epidemic and management model that realistically and adequately incorporates fungicide effects on disease development.

\section{ACKNOWLEDGMENTS}

I thank S. Seguin for excellent technical assistance in the experiments and for drawing Figure 1.

\section{LITERATURE CITED}

1. Browder, L. E. 1971. Pathogenic specialization in cereal rust fungi, especially Puccinia recondita f. sp. tritici: Concepts, methods of study, and application. U. S. Dep. Agric. Tech. Bull. 1432.

2. Buck, J. W., and Williams-Woodward, J. L. 2003. The effect of fungicides on urediniospore germination and disease development of daylily rust. Crop Prot. 22:135-140.

3. Dickens, J. S. W. 1990. Studies on the chemical control of chrysanthemum white rust caused by Puccinia horiana. Plant Pathol. 39:434-442.

4. Godwin, J. R., Anthony, V. M., Clough, J. M., and Godfrey, C. R. A. 1992. ICIA 5504: A novel, broad spectrum, systemic $B$ methoxyacrylate fungicide. Pages 435-442 in: Brighton Crop Prot. Conf.-Pests and Diseases, vol. 1. Lavenham Press, Lavenham, Suffolk, UK.

5. Gold, R. E., and Leinhos, G. M. 1995. Fungicidal effects of BAS $490 \mathrm{~F}$ on the development and fine structure of plant pathogenic fungi. Pestic. Sci. 43:250-253.

6. Hampton, J. G. 1986. Fungicidal effects on stem rust, green leaf area, and seed yield in Grasslands Nui' perennial ryegrass. N. Z. J. Exp. Agric. 14:7-12.

7. Koller, W. 1994. Chemical control of apple scab - Status quo and future. Norw. J. Agric. Sci. S17:149-170.

8. Kuck, K. H., Scheinpflug, H., and Pontzen, R. 1995. DMI fungicides. Pages 205-258 in: 
Modern Selective Fungicides: Properties, Applications, Mechanisms of Action, 2nd ed. H. Lyr, ed. Gustav Fischer Verlag, New York.

9. Leroux, P. 1996. Recent developments in the mode of action of fungicides. Pestic. Sci. 47:191-197.

10. Mueller, D. S., Jeffers, S. N., and Buck, J. W. 2004. Effect of timing of fungicide applications on development of rusts on daylily, geranium, and sunflower. Plant Dis. 88:657-661.

11. Mueller, D. S., Jeffers, S. N., and Buck, J. W. 2005. Toxicity of fungicides to urediniospores of six rust fungi that occur on ornamental crops. Plant Dis. 89:255-261.

12. Pfender, W. F. 2001. A temperature-based model for latent period duration in stem rust of perennial ryegrass and tall fescue. Phytopathology 91:111-116.

13. Pfender, W. F. 2003. Prediction of stem rust infection favorability, by means of degree-hour wetness duration, for perennial ryegrass seed crops. Phytopathology 93:467-477.

14. Pfender, W. F. 2004. Role of phenology in host susceptibility and within-plant spread of stem rust during reproductive development of perennial ryegrass. Phytopathology 94:308-316.

15. Pontzen, R., and Scheinpflug, H. 1989. Effects of triazole fungicides on sterol biosynthesis during spore germination of Botrytis cinerea, Venturia inaequalis, and Puccinia graminis f. sp tritici. Neth. J. Plant Pathol. (Suppl. 1) 95:151-160.
16. Szkolnik, M. 1981. Physical modes of action of sterol-inhibiting fungicides against apple diseases. Plant Dis. 65:981-985.

17. Welty, R. E., and Azevedo, M. D. 1994. Application of propiconazole in management of stem rust in perennial ryegrass grown for seed. Plant Dis. 78:236-240.

18. Wong, F. P., and Wilcox, W. F. 2001. Comparative physical modes of action of azoxystrobilurin, mancozeb, and metalaxyl against Plasmopara viticola (grapevine downy mildew). Plant Dis. 85:649-656.

19. Ypema, H. L., and Gold, R. E. 1999. Kresoxim-methyl: Modification of a naturally occurring compound to produce a new fungicide. Plant Dis. 83:4-19. 